\title{
TRANSFORMASI BENTUK TOKOH PUTREN WAYANG KULIT PURWA DEWI RENUKA
}

\author{
Hayati $^{1}$, Dendi Pratama ${ }^{2}$ \\ Program Studi Desain Komunikasi Visual, \\ Fakultas Bahasa dan Seni, Universitas Indraprasta PGRI \\ Jl. Nangka No. 58 C, Tanjung Barat, Jakarta 12530, Indonesia \\ hayatiptrusnadi@gmail.com
}

\begin{abstract}
Abstrak
Wayang Kulit Purwa adalah suatu karya seni yang memiliki kisah-kisah yang dapat dijadikan gambaran bagi kehidupan manusia. Dalam Wayang Kulit Purwa terdapat beberapa tokoh yang terlibat dalam pagelaran dan pementasannya antara lain: Tokoh Ksatria, Tokoh Raja, dan Tokoh Putren. Dalam artikel ini akan dibahas salah satu tokoh putri, yaitu bentuk tokoh Wayang Dewi Renuka sebagai pembelajaran semasa hidupnya dalam bentuk boneka wayang yang berbeda dari Dewi Renuka.
\end{abstract}

Kata Kunci: Wayang Kulit Purwa, Dewi Renuka.

\begin{abstract}
Wayang kulit purwa is a work of art that has stories that can be used as images for human life. In Purwa Wayang Kulit there are several figures involved in the performance and performances, among others: Ksatria Leaders, King Figures and Putren Figures. In this article one of the female characters will be discussed, namely the form of the figure of wayang Dewi Renuka for learning during her life in the form of a different puppet doll from Dewi Renuka.
\end{abstract}

Keywords: Purwa Leather Puppet, Dewi Renuka.

\section{PENDAHULUAN}

Wayang kulit purwa merupakan salah satu bentuk lokal genius yang menjadi media unik bagi masyarakat Jawa untuk mengekspresikan cita-cita hidupnya. Kepandaian genius lokal Jawa dalam mengelaborasi berbagai pandangan luhur budaya lain (Hindu/Buddha dan pada akhirnya Islam) menjadikan masyarakat Jawa kaya akan berbagai nilai-nilai kehidupan. Menurut Bennedict (2003), pertunjukan Wayang Kulit Purwa seperti halnya sistem etika dan metafisika lainnya, bermaksud menjelaskan tentang alam semesta Wayang Purwa memiliki kaitan dengan kegiatan berbudaya dan memiliki dua fungsi utama dalam pertunjukannya. Pertama adalah berfungsi sebagai sarana pengungkap kreativitas seni dan yang kedua berfungsi sebagai sarana komunikasi dalam berbagai kepentingan (Suwarno, 2016). Fungsi ganda tersebut akhirnya dimanfaatkan oleh para ahli dalam berbagai hal tanpa menimbulkan masalah di masyarakat luas (Akbar, 2014).

Dalam Wayang Kulit Purwa terdapat beberapa tokoh yang terlibat dalam pagelaran dan pementasannya antara lain: Tokoh Ksatria, Tokoh Raja, Tokoh Raksasa, dan Tokoh Putren. Dalam artikel ini akan dibahas mengenai Tokoh Putren atau Putri, yaitu Dewi Renuka. Dewi Renuka adalah Tokoh Pewayangan dari cerita Ramayana yang merupakan putri Prabu Prasnajid. Dewi Renuka menikah dengan Prabu Jamadagni, raja negara Kanyakawaya, putra Brahmana 
Ricika dengan Dewi Setyawati. Dari perkawinan dengan Prabu Jamadagni Dewi Renuka mempunyai lima orang putra lelaki dan putra bungsunya bernama Ramaparasu.

Dewi Renuka semasa hidupnya menghadapi masa transisi dari kehidupan kemewahan dalam kerajaan. Kemudian harus hidup dalam kesederhanaan di pertapaan yang harus mengendalikan diri dari segala kepentingan duniawi. Pada saat proses perubahan hidupnya Dewi Renuka mengalami perasaan gundah gulana saat proses transisi kehidupannya (Suwarno, 2016).

Dewi Renuka mempunyai tiga bentuk berbeda dalam wayang kulit purwa, setiap bentuk dari Dewi Renuka merupakan proses transisi kehidupannya dan dalam pembahasan ini yang digunakan yaitu pada boneka Wayang Kulit Purwa koleksi Bambang Suwarno. Berdasarkan penjelasan di atas, maka pada penelitian ini akan dijelaskan perubahan bentuk atau transformasi Dewi Renuka.

\section{METODE PENELITIAN}

Waktu penelitian dilaksanakan secara berkala sejak bulan Maret sampai bulan Juli 2018 di Solo, Jawa Tengah. Peneliti menggunakan beberapa metode yang disesuaikan, adapun data penelitian yang didapat dari hasil penelitian, yaitu meliputi studi pustaka, observasi, dan wawancara. Peneliti menggunakan jenis penelitian kualitatif dengan menggunakan teknik pengumpulan data melalui studi kepustakaan berupa buku, jurnal, dan website yang berkaitan pada materi yang mendukung penelitian ini. Selain itu, dilakukannya observasi dengan mengamati langsung bagaimana perbedaan bentuk Tokoh Putren dari Dewi Renuka dan melakukan wawancara untuk mengenal Tokoh Putren pada Wayang Kulit Purwa Dewi Renuka dan karakter serta cerita pada Tokoh Putren wayang tersebut.

\section{HASIL DAN PEMBAHASAN}

Dewi Renuka dikaruniai penampilan seperti dara remaja walau telah mempunyai lima orang putra. Dewi Renuka merupakan putri Prabu Prasnajid. Dewi Renuka menikah dengan Prabu Jamadagni, raja negara Kanyakawaya, putra Brahmana Ricika dengan Dewi Setyawati. Dari perkawinan dengan Prabu Jamadagni Dewi Renuka mempunyai lima orang putra lelaki dan putra bungsunya bernama Ramaparasu. Ketika Prabu Jamadagni memutuskan untuk hidup sebagai brahmana, Dewi Renuka dan kelima putranya ikut dibawa ke pertapaan Dewasana. Mereka hidup dalam kebahagiaan sampai suatu peristiwa sedih melanda kehidupan mereka.

Pada suatu ketika Dewi Renuka tertarik oleh ketampanan Prabu Citarata dan mereka melakukan perkawinan gandarwa (perselingkuhan seksual). Perselingkuhan tersebut itu diketahui Resi Jamadagni yang menyuruh Ramaparasu untuk membunuh Dewi Renuka sebagai upaya penebusan dosa. Kemudian, Dewi Renuka dihidupkan kembali oleh Resi Jamadagni atas permintaan Ramaparasu.

Dewi Renuka kembali hidup dan berbahagia bersama suami dan kelima putranya sampai suatu malapetaka menimpa kebahagiaan mereka. Pertapaan Dewasana diserang balatentara Prabu Hehaya dan Resi Jamadagni gugur dalam peperangan. Kesedihan Dewi Renuka semakin bertambah, ketika Ramaparasu pergi meninggalkan pertapaan Dewasana dan menggembara untuk melaksanakan sumpahnya, yaitu akan membunuh semua satria yang dijumpainya. Akhir riwayat Dewi Renuka diceritakan meninggal dalam kesedihan setelah satu persatu dari ke empat putranya meninggal dunia.

\section{Bentuk visual wayang Dewi Renuka}

Bentuk visual wayang Dewi Renuka terdiri dari tiga bentuk yang berbeda, yaitu;

1. Gambar Dewi Renuka ketika Masih Muda 


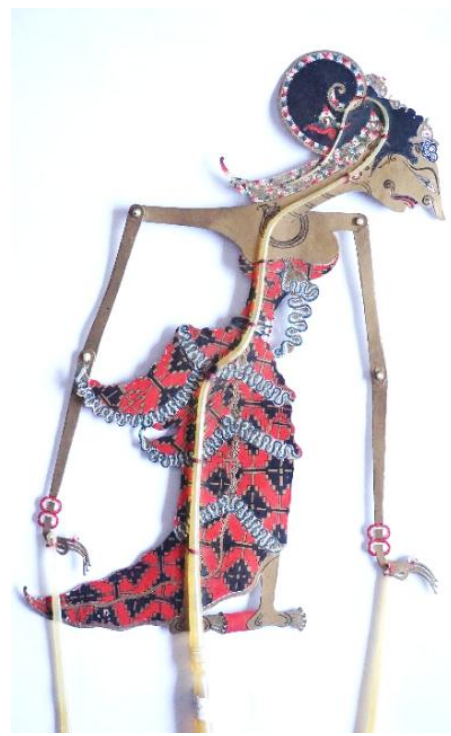

Gambar 1 Dewi Renuka Muda

Sumber: Bambang Suwarno, 2014

Pada gambar pertama ini menunjukkan bahwa Dewi Renuka menggunakan aksesoris gelungan rambut yang berwarna merah, melambangkan Dewi Renuka saat masih muda masih menjaga penampilannya agar terlihat cantik dan menarik bagi para lelaki yang memandangnya dengan menggunakan aksesoris gelungan pada rambutnya tersebut. Selain mengguakan aksesoris pada bagian kepala dan rambut pada Dewi Renuka saat muda juga menggunakan aksesoris kalung yang melingkar pada bagian leher Dewi Renuka, serta aksesoris lainnya, yaitu pada pergelangan tangan. Pada kedua pergelangan tangan Dewi Renuka menggunakan gelang yang warna dan bentuknya sama berwarna merah dan bulat. Selain menggunakan aksesoris Dewi Renuka menggunakan busana samparan. Samparan merupakan jenis kampuh yang digunakan oleh Tokoh Putren. Samparan yang dgunakan pada Tokoh Putren Dewi Renuka menggunakan warna merah yang bercorak warna hitam dan pada busananya tersebut Dewi Renuka juga menggunakan lengseng pada bagian dadanya yang menjulur sampai pinggang agar dapat menjadi pusat perhatian yang melihatnya.

2. Gambar Dewi Renuka ketika Menikah dengan Prabu Jamadagni

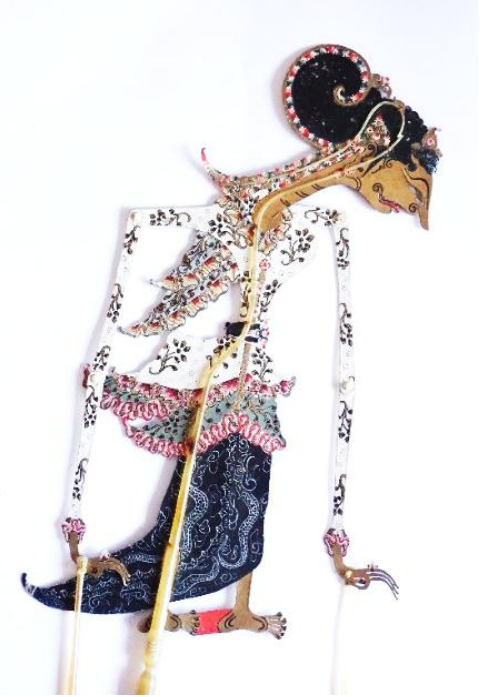

Gambar 2 Dewi Renuka ketika Menikah Sumber: Bambang Suwarno, 2014 
Pada gambar kedua ini menunjukkan pada bagian kepala pada Dewi Renuka tidak menggunakan aksesoris gelungan rambut seperti pada gambar yang pertama. Hal itu dikarenakan setelah menikah dengan Prabu Jamadagni Dewi Renuka sudah mempelajari kehidupan dan sudah mempunya 5 orang putra. Pada bagian badan Dewi Renuka menggunkan busana yang panjang, yaitu menggunakan busana berwarna putih yang melambangkan kesucian dan pada busana tersebut bercorak bunga-bunga. Pada gambar kedua ini juga Dewi Renuka sudah tidak menggunakan aksesoris pada leher maupun pada kedua pergelangan tangannya serta sudah tidak menggunakan aksesoris pada busanana, yaitu lengseng. Hanya menggunakan busana berwarna putih panjang dan dipadukan dengan menggunakan songket atau rok berwarna hitam yang putih dan juga berwarna hijau pada bagian pinggang Dewi Renuka. Pada bagaian kaki juga sama seperti pada gambar Dewi Renuka pertama tidak menggunakan aksesoris atau sejenisnya.

\section{Gambar Dewi Renuka ketika Berserah kepada Allah}

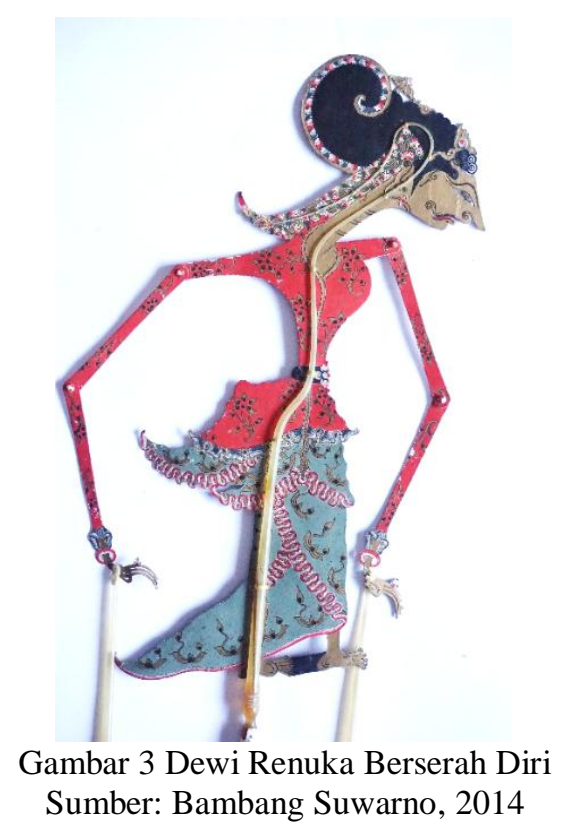

Pada gambar ketiga ini bagian kepala Dewi Renuka tidak menggunakan aksesoris sama seperti pada gambar kedua. Pada gambar ini Dewi Renuka hanya menggunakan aksesoris binggel pada kedua pergelangan tangannya, gelang tersebut berwarna merah dan bulat serta hanya menggunakan masing-masing satu pada pergelangan tangannya, berbeda pada gambar Dewi Renuka pertama dengan menggunakan gelang masing-masing berjumlah dua. Pada bagian badan gambar ketiga ini Dewi Renuka menggunakan busana yang panjang sama seperti gambar kedua, tetapi pada busana ini Dewi Renuka menggunakan warna merah yang bercorak bunga dan menggunakan rok atau songket berwarna hijau muda. Pada gambar ini juga Dewi Renuka tidak sama seperti gambar kedua tidak menggunakan lengseng seperti pada gambar pertama. Dan juga pada bagian kaki sama seperti gambar-gambar sebelumnya tidak menggunakan aksesoris dan sejenisnya. 


\section{Transisi Kehidupan Dewi Renuka}

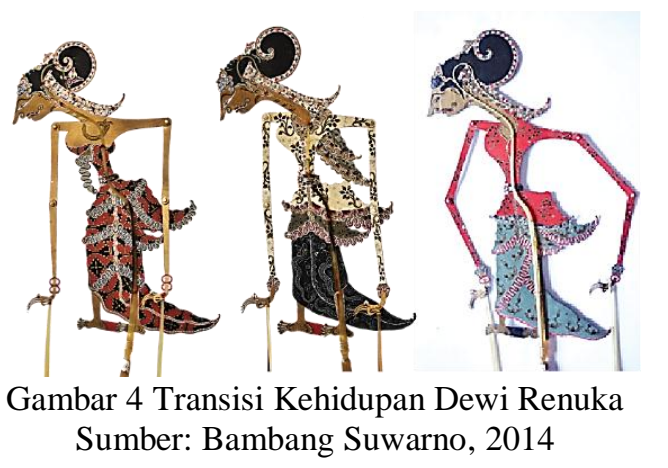

Pada gambar di atas menceritakan transisi kehidupan Dewi Renuka. Dilihat dari ketiga bentuk masing-masing wayang Dewi Renuka memiliki perbedaan bentuk. Pada gambar ini menunjukan pada bagian kepada pada Dewi Renuka menggunakan gelungan rambut yang terdapat pada kepala yang berwarna merah

a. Pada saat Dewi Renuka masih muda dan haus akan kekayaan duniawi, Dewi Renuka hanya memikirkan tentang duniawi saja maupun harta. Bisa dilihat dari busana yang digunakan hanya menggunakan busana yang minim dan memakai aksesoris busana seperti; gelang kana pada kedua pergelangan tangannya, gelungan rambut yang memakai aksesoris berwarna merah dan juga memakai lungseng pada busananya.

b. Pada saat Dewi Renuka memulai akan kehidupan pernikahan-nya dengan Jamadagni yang dikaruniai lima orang putra. Dewi Renuka menjalani kehidupan yang bahagia dan mulai menata diri untuk menjadi lebih baik dan mendekatkan dirinya kepada Allah Swt. Bisa dilihat dari busana yang digunakan menggunakan busana yang lebih tertutup berwarna putih yang melambangkan akan pembelajaran kesucian semasa hidupnya, tidak memakai aksesoris pada kepala dan busananya.

c. Setelah pernikahannya dan Dewi Renuka berselingkuh membuat suami Dewi Renuka murka. Hal itu membuat Dewi Renuka semakin pasrah dan makin mendakatkan dirinya kepada sang penciptnya. Bukti perilaku tersebut bisa dilihat dari busana yang digunakan, yaitu pakaian tertutup dan sederhana tanpa menggunakan aksesoris kalung maupun kepala hanya menggunakan gelang binggel.

\section{SIMPULAN}

Simpulan yang dapat diambil dari penelitian ini adalah bahwa bentuk dari setiap Tokoh Wayang Kulit Purwa disesuaikan dengan konsep ekspresif, dekoratif, humoris, dan karikatural itu bukan mengarah pada bentuk fisik dari tokoh yang digambarkan, melainkan sifat atau karakternya. Seperti pada hasil dari penelitian dari koleksi Wayang Putren dari Dewi Renuka.

Bahwa dari hasil penilitian bentuk-bentuk wayang dari ketiga boneka wayang Dewi Renuka mempunyai arti dan makna yang dapat menjelaskan tentang suasana hati tokoh wayang, karakter wayang, penggambaran waktu dan momen pada setiap tokoh wayang. Sifat-sifat yang digambarkan dalam karakter Wayang Kulit Purwa juga merupakan gambaran karakter-karakter manusia di dunia. Demikian juga gambaran sifat dan kehidupan tokoh perempuan dalam pergelaran Wayang Kulit Purwa yaitu Dewi Renuka.

Untuk ikut melestarikan kebudayan wayang kulit purwa terutama karakter karakter pada berbagai macam tokoh wayang kulit purwa agar warisan budaya dapat terus dilanjutkan ke generasi selanjutnya, bagi anak Indonesia juga di harapkan untuk lebih peduli terhadap budaya penuh nilai dan makna yang kita miliki dan untuk turut bangga dan mengambil andil dalam pengembangannya. 


\section{DAFTAR PUSTAKA}

Akbar, T. (2016). Wayang kulit glow in the dark. Jurnal Desain, 2(02), 99-110.

Bennedict, A. R. G. (2003). Mitologi dan toleransi orang Jawa. Yogyakarta: Bentang Budaya.

Suwarno, B. (2014). Kajian bentuk dan fiungsi wanda wayang kulit purwa gaya Surakarta kaitannya dengan pertunjukan. Institut Seni Indonesia Surakarta: Surakarta.

Suwarno, B., Haryono, T., Soedarsono, R. M., \& Soetarno, S. (2016). Kajian bentuk dan fungsi wanda wayang kulit purwa gaya Surakarta, kaitannya dengan pertunjukan. Gelar: Jurnal Seni Budaya, 12(1). 1-10. 